\title{
BMJ Open Applying the Three Delays Model to understand emergency care seeking and delivery in rural Bangladesh: a qualitative study
}

\author{
Bansari Shah, ${ }^{1}$ Nandita Krishnan (D) , ${ }^{2}$ Stephen R. Kodish, ${ }^{3}$ Gayane Yenokyan, ${ }^{4}$ \\ Kaniz Fatema, ${ }^{5}$ Kazi Burhan Uddin, ${ }^{5}$ A K M Fazlur Rahman, ${ }^{5}$ Junaid Razzak ${ }^{1}$
}

To cite: Shah B, Krishnan N, Kodish SR, et al. Applying the Three Delays Model to understand emergency care seeking and delivery in rural Bangladesh: a qualitative study. BMJ Open 2020;10:e042690. doi:10.1136/ bmjopen-2020-042690

- Prepublication history and additional material for this paper are available online. To view these files, please visit the journal online (http://dx.doi. org/10.1136/bmjopen-2020042690).

Received 20 July 2020 Revised 19 November 2020 Accepted 24 November 2020

Check for updates

(c) Author(s) (or their employer(s)) 2020. Re-use permitted under CC BY-NC. No commercial re-use. See rights and permissions. Published by BMJ.

For numbered affiliations see end of article.

Correspondence to Nandita Krishnan; nkrishnan@gwu.edu

\section{ABSTRACT}

Objectives The Three Delays Model has been commonly used to understand and prevent maternal mortality but has not been systematically applied to emergency medical conditions more generally. The objective of this study was to identify delays in emergency medical care seeking and delivery in rural Bangladesh and factors contributing to these delays by using the Three Delays Model as a framework.

Design A qualitative approach was used. Data were collected through focus group discussions and in-depth interviews using semistructured guides. Two analysts jointly developed a codebook iteratively and conducted a thematic analysis to triangulate results.

Setting Six unions in Raiganj subdistrict of Bangladesh. Participants Eight focus group discussions with community members $(n=59)$ and eight in-depth interviews with healthcare providers.

Results Delays in the decision to seek care and timely receipt of care on reaching a health facility were most prominent. The main factors influencing care-seeking decisions included ability to recognise symptoms and decision-making power. Staff and resource shortages and lack of training contributed to delays in receiving care. Delay in reaching care was not perceived as a salient barrier. Both community members and healthcare providers expressed interest in receiving training to improve management of emergency conditions.

Conclusions The Three Delays Model is a practical framework that can be useful for understanding barriers to emergency care and developing more tailored interventions. In rural Bangladesh, training community members and healthcare providers to recognise symptoms and manage acute conditions can reduce delays in care seeking and receiving adequate care at health facilities.

\section{INTRODUCTION}

Twenty-four million deaths related to emergency medical conditions occur in low/ middle-income countries (LMICs) annually, accounting for an estimated 1023 million disability-adjusted life years (DALYs) and 932 million years of life lost. ${ }^{1}$ This includes both communicable and non-communicable
Strengths and limitations of this study

- This is one of few studies to apply the Three Delays Framework to the broader context of emergency medical conditions.

- Purposive sampling of subgroups of community members and healthcare providers facilitated data triangulation.

- Participants were identified by local community leaders and their views may not be representative of all potential participants.

- Due to logistical constraints, data were collected in only six of nine unions, potentially limiting generalisability.

diseases, with ischaemic heart disease and cerebrovascular disease causing the highest mortality burden, and unintentional injuries causing the most DALYs. ${ }^{1}$ In Bangladesh, stroke and ischaemic heart disease are the leading causes of death. ${ }^{2}$ Additionally, unintentional injuries contribute to a large burden of premature death. For instance, drowning ${ }^{3}$ and road traffic injuries ${ }^{4}$ result in substantial morbidity and mortality. Road traffic injuries exert a particularly high burden in rural Bangladesh and largely impact individuals between the ages of 25 and 64 years, a highly productive segment of the population. ${ }^{5}$ This burden could be reduced by improving emergency and acute care seeking and delivery.

Emergency care involves different levels of services, beginning with recognition of symptoms and care provided by laypersons at the scene of the injury or illness episode, and continuing through the care provided in a health facility. The quality and timeliness of care at each level are crucial to survival. The Three Delays Model, originally developed in the context of maternal mortality in lowincome settings, provides a useful framework to examine factors influencing the timeliness 
of care. ${ }^{6}$ According to this model, adverse outcomes from obstetric complications are attributable to three delays between the onset of complications and their ultimate outcome. The first delay is the delay in the decision to seek care, the second delay is related to reaching an appropriate health facility, and the third delay occurs once the patient reaches the health facility and waits to be seen by a medical professional. These delays are in turn influenced by socioeconomic factors, such as wealth and female education, cultural factors such as beliefs and customs, structural factors such as accessibility of care, and health system level factors such as quality of care.

While the literature is consistent on the factors influencing the three delays, the relative contribution of each of these delays varies across countries. A study in India ${ }^{7}$ found that the first two delays were the main contributors to maternal death, while a study in $\mathrm{Malawi}^{8}$ found that the third delay contributed the most to maternal death. Another study applied this model to understand care seeking and receipt for children with pneumonia in the Peruvian Amazon, and found that the first and third delays were most salient. ${ }^{9}$ Additionally, differences may exist across regions within countries. In rural areas, complications are more likely to result in adverse outcomes than in urban areas as all three delays in care seeking and delivery tend to be present and exert an interactive effect. ${ }^{7}$ A study on care seeking for obstetric complications in rural Bangladesh found that socioeconomic factors such as wealth, women's literacy and women's employment contributed to the delay in the decision to seek care, while service factors such as proximity to the health facility and availability of adequate obstetric services at the facility contributed to all three delays. ${ }^{10}$

The Three Delays Model has been widely applied to understand maternal mortality but it has not been systematically applied to the context of emergency medical conditions more broadly. This model could serve as a useful framework for developing and evaluating interventions for emergency medical conditions owing to similarities in the factors influencing care seeking and delivery for obstetric emergencies and other emergency medical conditions. ${ }^{11}$ Therefore, the aims of this study were: (1) to understand the contribution of the three delays to emergency care seeking and delivery in rural Bangladesh and identify factors influencing each of the delays, and (2) to obtain recommendations from providers and patients to improve emergency care. Findings can inform interventions aimed at reducing delays in emergency care seeking and delivery, and reduce the burden of morbidity and mortality from these conditions in rural Bangladesh.

\section{METHODS}

\section{Study setting}

This study was conducted in the Raiganj subdistrict of Bangladesh, a predominantly rural area with a population of about $318000 .{ }^{12}$ Raiganj is divided into nine unions. In

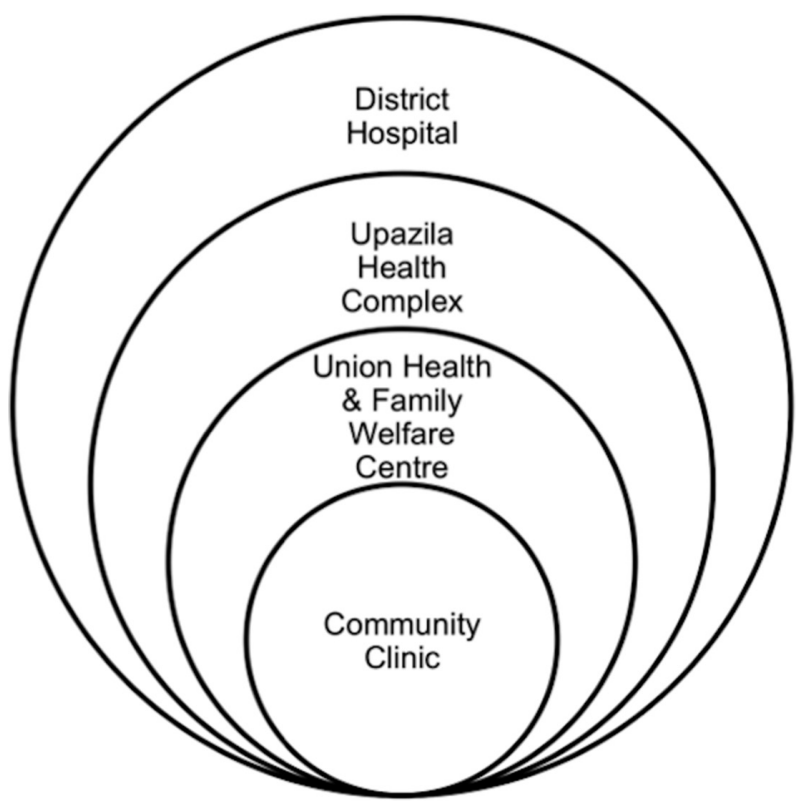

Figure 1 Structure of the public health system in Bangladesh.

each union, there are multiple community health centres (CHCs), which are the community's primary point of access to formal care. Each union also has one health and family welfare centre and child welfare clinic. For higher levels of care, each subdistrict has a health complex. The highest level of care is the district hospital, which delivers care in major specialty areas (figure 1).

\section{Study design and data collection}

An applied qualitative approach was used for this study, which included focus group discussions (FGDs) with community members and in-depth interviews (IDIs) with healthcare providers. Data collection took place in June 2016. Semistructured guides were used for FGDs and IDIs (online supplemental file 1). The semistructured format allowed for probing and follow-up questions to gain more clarity from participants. The interview guides for healthcare providers covered the themes of management of acute conditions in CHCs, services and resources available to manage these conditions, and provider perceptions of community members' awareness of where and when to seek care for emergency conditions. The focus group guide explored community members' perceptions of emergency conditions, how care-seeking decisions are made, and access to and availability of care. The guides were developed with the help of the Center for Injury Prevention and Research, Bangladesh (CIPRB) researchers using the rapid appraisal approach for community health assessments. The guides were developed in English, translated into Bengali and then back translated by CIPRB researchers.

FGDs and IDIs were conducted in six of the nine unions. A purposive sampling strategy was used to elicit perspectives from different groups of community members and different types of healthcare providers. Two FGDs were held with each of the following groups of stakeholders: 
men, women, the elderly and community leaders, for a total of eight FGDs $(n=59)$. In order to provide an open environment where participants felt comfortable sharing their thoughts, the FGDs with each stakeholder group were held separately. Eight IDIs were conducted with different types of healthcare providers: community health centre providers $(n=4)$, family welfare visitor $(\mathrm{n}=1)$, subassistant community medical officers $(\mathrm{n}=2)$, and upazila health and family planning officer $(n=1)$.

Community members were recruited by local community leaders. They were chosen based on their involvement in community affairs, availability and willingness to speak openly. Healthcare providers were recruited by CIPRB researchers. As there are limited healthcare providers in each community, we approached all of those who were available and willing to speak to us. All participants were over the age of 18 years. All FGDs and IDIs were conducted by two local public health field officers from CIPRB (KF and KBU). Both officers had significant field experience doing qualitative data collection and contributed to developing the guides. The FGDs and IDIs were digitally recorded with permission from participants. Field notes were also taken by the interviewers. All data were collected in Bengali, transcribed verbatim and translated into English for analysis by CIPRB researchers. On average, each interview/focus group lasted $30 \mathrm{~min}$.

\section{Data analysis}

Transcripts were analysed with a thematic approach using Dedoose V.7.6.21 (SocioCultural Research Consultants, Los Angeles, California, USA). The analysis combined an inductive and deductive approach. Two analysts (NK and SK) independently reviewed the transcripts and jointly developed a codebook, which consisted of some predefined themes as well as additional themes that emerged from the data. The same analysts independently coded extracts from multiple transcripts using the initial codebook and registered an intercoder reliability score of 0.75 . The analysts discussed discrepancies in the use of codes to ensure that codes were being applied uniformly. As additional themes and subthemes emerged, the analysts modified the codebook. The same analysts coded all transcripts using the final version of the codebook. Analytical memos were used to identify recurring patterns and themes in coded text segments.

\section{Patient and public involvement}

Patients or the public were not involved in the design, or conduct, or reporting, or dissemination plans of our research.

\section{RESULTS}

IDIs and FGDs revealed factors across a continuum of care affecting timeliness and quality of emergency medical services in rural Bangladesh. Salient themes surrounding factors affecting care are organised and presented according to the Three Delays Model:

\section{Delay 1: delayed decision to seek care}

The decision to seek care was influenced by several sociocontextual factors, most notably perceived severity of illness. Community members perceived symptoms such as high fever, cold, abdominal pain or fainting to be indicative of 'major problems'. They perceived a range of conditions to constitute emergencies, ranging from cuts, burns and poisoning, to drowning, accidents, stroke and heart attacks.

Greater distances from health facilities, high cost and negative past experiences at health facilities contributed to delays in deciding to seek care. However, perceived severity of illness superseded these other factors. If the illness was perceived to be very severe, participants reported that care was sought immediately regardless of these other factors as this focus group exchange with female community members illustrated:

Participant 5: During my pregnancy, at the time of delivery my water was broken but there was no pain, so we were waiting the whole night and went to the Shirajgonj hospital at the morning.

Moderator: Your water broke but you wait for morning, why not go to the hospital that time?

Participant 5: Because the time was midnight, so we wait for morning.

Moderator: If these types of emergency arise do you go as soon as possible or wait for some time?

Participant 3: No, no. When her mother-in-law became sick, they took her immediately.

Additionally, cultural factors including female decisionmaking power and role of traditional medicine influenced care-seeking decisions. The majority of participants reported that the decision to seek care was made by the head of the household, who was typically the husband. In some cases, family elders such as mothers-in-law made care-seeking decisions.

In our village we are very close to each other, we ask [advice from] one another and then take a decision where to go; mainly the family head takes the final decision. - Male community member

Based on these factors, for most community members, a clear hierarchy to care seeking existed (figure 2). The first line of care seeking, particularly for women, usually consisted of using home remedies or medications and consulting traditional village doctors or pharmacists at the local neighbourhood or 'bazaar'. For primary care and what they perceived as 'normal' illnesses, community members reported going to CHCs to seek treatment. For more serious issues such as pregnancy, care was usually sought at a health complex, which was perceived to have more staff and services than CHCs. For what they perceived as emergencies, community members reported seeking care at private clinics or hospitals, where they noted, 'doctors are available all the time'. 


\begin{tabular}{|c|c|c|c|c|}
\hline $\begin{array}{l}\text { Home and } \\
\text { Traditional Care } \\
\text { - Home remedies, } \\
\text { such as making } \\
\text { saline solution to } \\
\text { treat diarrhoea } \\
\text { - Purchase medicines } \\
\text { from pharmacists or } \\
\text { doctor in the local } \\
\text { bazaar }\end{array}$ & $\begin{array}{l}\text { Community Health } \\
\text { Clinics } \\
\text { - Primary care for } \\
\text { "minor problems", } \\
\text { such as fever, cold, } \\
\text { and to get medicines, } \\
\text { (although not always } \\
\text { available) } \\
\text { - Providers refer } \\
\text { anything more serious } \\
\text { to a health complex or } \\
\text { hospital }\end{array}$ & $\begin{array}{l}\text { Health Complexes } \\
\text { - Treatment for } \\
\text { "normal diseases" } \\
\text { and uncomplicated } \\
\text { deliveries } \\
\text { - More serious injuries/ } \\
\text { diseases than at } \\
\text { community health } \\
\text { clinics } \\
\text { - Quality of service not } \\
\text { always good }\end{array}$ & $\begin{array}{l}\text { Hospitals } \\
\text { - Emergency care and } \\
\text { treatment for "major } \\
\text { problems" such as high } \\
\text { fever, abdominal pain, } \\
\text { complicated delivery, } \\
\text { major trauma such as } \\
\text { fractures } \\
\text { - Important for receiving } \\
\text { care after hours } \\
\text { because doctors and } \\
\text { nurses will be available }\end{array}$ & $\begin{array}{l}\text { Private Clinics } \\
\text { - Many doctors in } \\
\text { government hospitals } \\
\text { suggest their own } \\
\text { private practice } \\
\text { clinics } \\
\text { - Patients often go } \\
\text { here directly for } \\
\text { emergency care } \\
\text { - Better quality of care } \\
\text { but more expensive }\end{array}$ \\
\hline
\end{tabular}

LESS SERIOUS

MORE SERIOUS
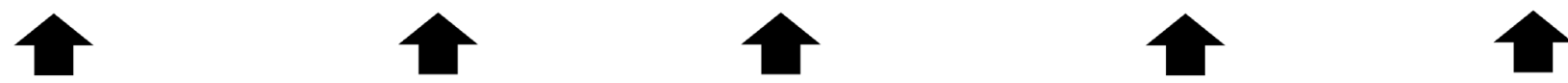

Contextual Factors

Proximity, Cost, Past experience, Perceived severity of illness

Figure 2 Continuum of care-seeking behaviour as explained by community members in rural Bangladesh.

Q: If any one of you or your family members get sick where do you go first?

R: At first, we go to the community clinic, then local pharmacy and if it is getting serious than go to the upazila health complex or district hospital. But upazila health complex doesn't give good service so most of the time we go to the private clinic. - Male community member

\section{Delay 2: delayed arrival at health facility}

When decisions to seek care were made, participants reported that CHCs were largely accessible for most community members. A few participants reported that delays in transportation made it difficult to quickly reach higher level health facilities in the event of an emergency condition, but most participants said that transportation was not an issue and several modes, such as rickshaws and vans were available. Distances to hospitals varied depending on the union. In some unions, hospitals were between 3 and $5 \mathrm{~km}$ away from the village and took approximately $15-20 \mathrm{~min}$ to reach, but in some unions, the nearest hospital was $10-20 \mathrm{~km}$ away and took more than an hour to reach.

Community members mostly rely on arranging their own transportation to health facilities. According to CHC providers, patients had good knowledge and awareness of where to seek care but for some patients, distance and cost could be barriers in this setting.

If any accident patient is very serious then they directly go to the hospital, because they know we can't handle that. - Upazila health and family planning officer

\section{Delay 3: delayed provision of adequate care}

CHCs represent the first point of entry into the formal healthcare system. However, lack of adequate training of providers and shortage of resources and staff contributed to delays in patients receiving care at these facilities. CHC providers explained that they were only able to provide basic first aid for injuries and accidents. In case of more complex conditions, they referred patients to the nearest hospital or health complex to manage emergency conditions.

Mainly we give first aid treatment and health education for diarrhoa, fever, cold etc. If any patient came with a serious problem then we referred them to the health complex for better treatment. - Community health centre provider

CHCs reported carrying medicines and supplies for basic first aid, family planning, pregnancy-related supplementation and common illnesses such as fever. However, stock-outs were common and community members indicated that people got medicines 'depending on availability'.

Most CHCs were equipped with basic equipment such as blood pressure machines and glucometers, with some exceptions. While more sophisticated medical equipment such as nebulisers and X-ray machines were available in the upazila health complex, lack of training and infrastructure were barriers to their utilisation within clinics.

We have an operation room but it's not used, we need a surgeon and anesthetist for that. We have x-ray machine but it is not working. - Upazila health and family planning officer 
CHCs varied in terms of number of staff members available during working hours, ranging from one to four individuals. CHCs had a mix of office-level and field-level staff and specialised providers such as gynaecologists were not commonly reported. Clinic staff reported that CHCs were open 6 days a week, for approximately 6 hours each day. However, according to community members, CHCs are open only for $4-5$ days a week, for about 3-4hours each day. A community elder remarked: "if we go to the clinic after $1 \mathrm{pm}$, they say it's closed." In contrast, the hospitals were open 24 hours, 7 days a week, but hospitals are farther away from CHCs for most people in need of urgent care.

Additionally, some community members felt that on reaching hospitals, patients were prioritised based on connections they had with doctors or ability to pay, which resulted in delays in being seen by a healthcare provider and receiving treatment. Community members also felt that shortage of resources such as medications contributed to delays in receiving timely care once they reached the health facility:

Raigonj hospital has no medicine and Jia medical also has very limited medicine. Last week I go to Jia medical college hospital to visit a patient and it was a very helpless situation. - Community elder

\section{Recommendations to improve emergency care Providers}

Providers expressed a need for and interest in receiving more training to handle acute conditions. They felt that this could help prevent deaths and save time and money for patients. Providers also felt that patients did not have confidence in their abilities and skills. Providers wanted to learn more about management of emergency conditions.

[We need] gauze, bandage and suturing materials but we have very limited knowledge on suturing and other subjects. If we get some training on it, then we can provide a better service. - Community health centre provider

Emergency management of acute care, acute MI (myocardial infarction), near drowning, shockthis type of management training we need the most. Sometimes we refer patient for treatment but patient dies on the road. If we can manage it here, the life can be saved. - Upazila health and family planning officer

Providers also recommended that the supply of medicines to the CHCs be improved, particularly for antibiotics, which were often in low supply and expensive for patients to purchase. Other needs expressed by providers were having more trained staff in CHCs, particularly trained doctors, surgeons and assistants, and better infrastructure.
Community members

Community members felt that providers at CHCs were insufficiently trained and could only provide basic primary care. They also felt that providers were not good at diagnosing illnesses and could only treat 'common' diseases such as fever and cold. Another concern was that many providers were more invested in their own private practices and therefore did not offer adequate care to patients at the CHC. Community members suggested enforcing better regulations over doctors with private practices as well as eliminating favouritism towards patients.

Community members noted cyclical shortages of medicines at the CHCs and felt that better monitoring of supply by authorities could address these shortages. They were also concerned that providers at CHCs were prescribing unnecessary medications based on what was available rather than what was required.

Like providers, community members felt that more trained staff and equipment were needed at CHCs.

We need a full time doctor here for any emergency. In case of any emergency like heart disease, he/she can manage it immediately. - Female community member

Community members were enthusiastic about receiving training to provide first aid and manage acute conditions. A few women mentioned that they already received training as caregivers, known as Anchal Mas, to deliver basic first aid.

If any children cut his or her hand or leg came to me, I have first aid training from CIPRB. I was an Anchal Ma. I have cotton gauze and medicine, so they came to me. At first, I clean the wound, then put the bandage. - Female community member

\section{DISCUSSION}

In rural Bangladesh, we found that several sociocontextual factors influenced care-seeking decisions, which could contribute to delays in the decision to seek care. Delays in receiving care at the health facility were also a barrier to timely management of emergency conditions, whereas delays in reaching health facilities were less of a primary concern due to a tiered health system with multiple levels of care available to most of the population.

Factors contributing to care-seeking decisions included perceived severity of illness, proximity to and timings of health facilities, cost of care and past experiences receiving care. Among these, perceived illness severity appeared to be the strongest factor influencing decision-making. Determining severity of an illness episode depends on the ability of community members to recognise signs and symptoms of acute conditions. Although community members differentiated between 'normal' and 'emergency' conditions, basing care-seeking decisions on the severity of symptoms is limited by individual capacity to understand what is biomedically urgent. Moreover, 
seemingly mild or non-specific symptoms, such as nausea, could be indicative of serious conditions such as myocardial infarctions. ${ }^{13}$ Prior research has shown that the inability to recognise symptoms is a barrier to timely care seeking, ${ }^{7}$ and that awareness of symptoms for emergency conditions such as heart attacks and stroke is low. ${ }^{14} 15$ Therefore, an important component of a communitybased programme might include education sessions focused on screening and identifying signs and symptoms of life-threatening versus less serious conditions.

We also found that in this context, cultural factors such as the strong role of traditional medicine, as well as the weak decision-making power, particularly for younger women, underpin health-related decisions. Of all the demographic groups, women were more likely to report first seeking care from the village doctor. This could stem from gender norms in Bangladesh, which dictate that women should remain at home and should be accompanied by men in public spaces. ${ }^{16}$ As village doctors are located closer to home, it may be easier and more acceptable for women to go to the 'bazaar' unaccompanied. In this setting, successful interventions to improve emergency care seeking may need to target key decision makers, such as traditional healers, male heads of household or family elders. For instance, in Mozambique, traditional healers were used as part of successful intervention to increase referral rates to health facilities. ${ }^{17}$

Delayed provision of care occurs once the patient reaches the health facility and waits to be seen by a medical professional. Staffing and resource shortages often hindered the delivery of timely and high-quality medical care. We also found that community members felt that healthcare providers in CHCs lacked sufficient training to provide high-quality acute care, a view that was echoed by healthcare providers themselves. When individuals sought emergency care at CHCs, they were usually referred to the health complex or hospitals as CHCs lacked the resources and capacity to treat these conditions. This resulted in delays that could be avoided if $\mathrm{CHCs}$ received adequate resources and providers are trained in management of emergency conditions. Building capacity of CHC providers in the management of emergency conditions can reduce the need for referrals. Even if referrals are required, better management of emergency conditions at the CHC level can stabilise the patient's condition, improving the likelihood of a favourable outcome once the patient reaches the tertiary healthcare facility. We did find a high level of interest among healthcare providers to receive additional training in emergency care. Therefore, it may be possible to adapt successful emergency care training programmes from other similar countries to this setting. Compared with other LMICs where health worker attrition is high, ${ }^{18}$ rural Bangladesh has a community health worker (CHW) cadre which is prioritised and enjoys relatively good job security; therefore, investments in CHW training may see long-term improvements in health through better care practices and improved patient satisfaction. Improved monitoring and accountability systems are also needed to ensure that CHCs adequately serve patients.

Other research suggests that the community's delay in mobilising can be considered a fourth delay that hinders timely management of emergency conditions. ${ }^{19}$ In the case of emergency conditions such as drowning or road traffic injuries, even if the decision to seek care is made quickly, the delay in mobilising care from first responders at the scene of the illness episode can determine the outcome of the injury. Bystander education and awareness has been identified as an important factor influencing this delay, and a qualitative study on trauma delays for patients who had road traffic injury in Brazil found that bystander capacity to provide care was low. ${ }^{20}$ Simple interventions at the community level may be highly effective to mobilise first responders in low-resource settings. For example, interventions have included training commercial drivers in providing first aid ${ }^{21}$ and training laypeople to be first responders. ${ }^{22}$ In our study, community members were interested in receiving training in first aid and some had already received prior training. Community-based programmes have enjoyed much success in Bangladesh across a range of health conditions. ${ }^{23}$ Bangladesh started community-based programmes to address drowning and these programmes have shown an average DALY cost aversion of $\$ 362 .{ }^{24}$ Approaches from these programmes can be adapted to develop community-based education and training for the management of emergency conditions. In rural Bangladesh, community mobilisation strategies that involve multiple approaches combining education and training, as well as enhanced community infrastructure, may create enabling environments for improved outcomes from emergency medical conditions.

\section{Limitations}

Due to road access and weather limitations, data were only collected from six of the nine unions in Raiganj. Additionally, participants were identified by local community leaders and their views may not be representative of all community members; however, those individuals were sampled based on specific criteria we deemed important for answering the research questions, and purposive sampling is a strength of this type of research.

This study did have several strengths. First, by eliciting the voices of community members and healthcare providers, unique insights were gained that allowed for comparisons between the local and biomedical communities. Second, by including subgroups of community members (eg, men, women, elders and community leaders) and as well as subgroups of healthcare providers (eg, doctors, nurses, CHWs), participant triangulation was achieved.

\section{Conclusions}

In rural Bangladesh, the health system has a far reach through a multi-tiered network of providers. However, several sociocontextual factors influence care-seeking decisions and could contribute to delays in deciding to 
seek care, while lack of adequate training and manpower, and resource shortages resulted in delays in receiving care at the health facility. Both these factors could contribute to adverse outcomes from emergency medical conditions. While better infrastructure and resources are necessary, improvements in emergency care delivery in this setting may be achieved through modest, yet targeted behavioural change interventions, such as training of community members and healthcare providers.

\section{Author affiliations}

${ }^{1}$ Emergency Medicine, Johns Hopkins School of Medicine, Baltimore, Maryland, USA ${ }^{2}$ Prevention and Community Health, The George Washington University Milken Institute of Public Health, Washington, DC, USA

${ }^{3}$ Nutritional Sciences and Biobehavioral Health, Pennsylvania State University, University Park, Pennsylvania, USA

${ }^{4}$ Biostatistics, Johns Hopkins University Bloomberg School of Public Health, Baltimore, Maryland, USA

${ }^{5}$ Center for Injury Prevention and Research, Dhaka, Bangladesh

\section{Twitter Junaid Razzak @JunaidRazzakMD}

Contributors BS conceived the study. BS designed the study protocol. NK and SK carried out the analysis and interpretation of these data. BS, NK and SK drafted the manuscript. GY, KF, KBU, AKMFR and JR critically revised the manuscript for intellectual content. All authors read and approved the final manuscript.

Funding This work was supported by the Paul S Lietman Global Travel Grant from the Johns Hopkins Center for Global Health.

Competing interests None declared.

Patient consent for publication Not required.

Ethics approval All participants provided informed oral consent. Ethical approval for this study was granted by the Johns Hopkins Medicine Institutional Review Board and the Ethical Review Committee of the Bangladesh Medical Research Council.

Provenance and peer review Not commissioned; externally peer reviewed.

Data availability statement Data are available upon reasonable request. Deidentified transcripts can be requested by emailing the lead author, Bansari Shah ( bansarishahmd@gmail.com)

Supplemental material This content has been supplied by the author(s). It has not been vetted by BMJ Publishing Group Limited (BMJ) and may not have been peer-reviewed. Any opinions or recommendations discussed are solely those of the author(s) and are not endorsed by BMJ. BMJ disclaims all liability and responsibility arising from any reliance placed on the content. Where the content includes any translated material, BMJ does not warrant the accuracy and reliability of the translations (including but not limited to local regulations, clinical guidelines, terminology, drug names and drug dosages), and is not responsible for any error and/or omissions arising from translation and adaptation or otherwise.

Open access This is an open access article distributed in accordance with the Creative Commons Attribution Non Commercial (CC BY-NC 4.0) license, which permits others to distribute, remix, adapt, build upon this work non-commercially, and license their derivative works on different terms, provided the original work is properly cited, appropriate credit is given, any changes made indicated, and the use is non-commercial. See: http://creativecommons.org/licenses/by-nc/4.0/.

ORCID iD

Nandita Krishnan http://orcid.org/0000-0003-4957-2061
REFERENCES

1 Hsia RY, Thind A, Zakariah A, et al. Prehospital and emergency care: updates from the disease control priorities, version 3. World J Surg 2015;39:2161-7.

2 Institute for Health Metrics and Evaluation (IHME). Bangladesh profile. Seattle, WA: IHME, University of Washington, 2018. http:// www.healthdata.org/bangladesh

3 Rahman A, Alonge O, Bhuiyan A-A, et al. Epidemiology of drowning in Bangladesh: an update. Int J Environ Res Public Health 2017; $14: 488$.

4 Global status report on road safety 2018. Geneva: World Health Organization; 2018. Licence: CC BYNC- SA 3.0 IGO. Available: https://www.who.int/violence_injury_prevention/road_safety_status/ 2018/en/

5 UI Baset MK, Rahman A, Alonge O, et al. Pattern of road traffic injuries in rural Bangladesh: burden estimates and risk factors. Int $J$ Environ Res Public Health 2017;14:1354.

6 Thaddeus S, Maine D. Too far to walk: maternal mortality in context. Soc Sci Med 1994;38:1091-110.

7 Sk MIK, Paswan B, Anand A, et al. Praying until death: revisiting three delays model to contextualize the socio-cultural factors associated with maternal deaths in a region with high prevalence of eclampsia in India. BMC Pregnancy Childbirth 2019;19:314.

8 Mgawadere F, Unkels R, Kazembe A, et al. Factors associated with maternal mortality in Malawi: application of the three delays model. BMC Pregnancy Childbirth 2017;17:219.

9 Pajuelo MJ, Anticona Huaynate C, Correa M, et al. Delays in seeking and receiving health care services for pneumonia in children under five in the Peruvian Amazon: a mixed-methods study on caregivers' perceptions. BMC Health Serv Res 2018;18:149.

10 Sikder SS, Labrique AB, Craig IM, et al. Patterns and determinants of care seeking for obstetric complications in rural northwest Bangladesh: analysis from a prospective cohort study. BMC Health Serv Res 2015;15:166.

11 Calvello EJ, Skog AP, Tenner AG, et al. Applying the lessons of maternal mortality reduction to global emergency health. Bull World Health Organ 2015;93:417-23.

12 Bangladesh Bureau of Statistics. Available: http://www. citypopulation.de/php/bangladesh-admin.php?adm2id=8861

13 Lu L, Liu M, Sun R, et al. Myocardial infarction: symptoms and treatments. Cell Biochem Biophys 2015;72:865-7.

14 Aminde LN, Takah N, Ngwasiri C, et al. Population awareness of cardiovascular disease and its risk factors in Buea, Cameroon. BMC Public Health 2017;17:545.

15 Hertz JT, Madut DB, Tesha RA, et al. Knowledge of myocardial infarction symptoms and perceptions of self-risk in Tanzania. Am Heart J 2019;210:69-74.

16 Ferdous J, Mallick D. Norms, practices, and gendered vulnerabilities in the lower Teesta Basin, Bangladesh. Environmental Development 2019;31:88-96.

17 Audet CM, Salato J, Blevins M, et al. Educational intervention increased referrals to allopathic care by traditional healers in three high HIV-prevalence rural districts in Mozambique. PLoS One 2013;8:e70326.

18 Willis-Shattuck M, Bidwell P, Thomas S, et al. Motivation and retention of health workers in developing countries: a systematic review. BMC Health Serv Res 2008;8:247.

19 MacDonald T, Jackson S, Charles M-C, et al. The fourth delay and community-driven solutions to reduce maternal mortality in rural Haiti: a community-based action research study. BMC Pregnancy Childbirth 2018;18:254.

20 Patel A, Vissoci JRN, Hocker M, et al. Qualitative evaluation of trauma delays in road traffic injury patients in Maringá, Brazil. BMC Health Serv Res 2017;17:804.

21 Mock CN, Tiska M, Adu-Ampofo M, et al. Improvements in prehospital trauma care in an African country with no formal emergency medical services. J Trauma 2002;53:90-7.

22 Husum H, Gilbert M, Wisborg T. Training pre-hospital trauma care in low-income countries: the 'Village University' experience. Med Teach 2003;25:142-8.

23 El Arifeen S, Christou A, Reichenbach L, et al. Community-Based approaches and partnerships: innovations in health-service delivery in Bangladesh. Lancet 2013;382:2012-26.

24 Rahman F, Bose S, Linnan M, et al. Cost-Effectiveness of an injury and drowning prevention program in Bangladesh. Pediatrics 2012;130:e1621-8. 